\title{
Adolescent survivor of childhood Acute Myeloid Leukaemia undertakes pregnancy with a severe anthracycline induced cardiomyopathy and risk taking behaviours
}

\author{
Anne Tripaydonis ${ }^{1}$, Rachel Conyers*2 \\ ${ }^{1}$ Melbourne Medical School, University of Melbourne, Melbourne, Australia \\ ${ }^{2}$ Children's Cancer Centre, Royal Children's Hospital, the Murdoch Childrens Research Institute, Melbourne, Australia
}

Received: July 11, 2016

DOI: $10.5430 /$ crim.v3n $4 p 64$
Accepted: September 27, 2016 Online Published: September 29, 2016

URL: http://dx.doi.org/10.5430/crim.v3n4p64

\begin{abstract}
A 16-year-old female survivor of childhood Acute Myeloid Leukaemia (AML) presented 12 weeks pregnant to her haematology oncology late effects appointment. Having failed to attend recent healthcare appointments her severe cardiomyopathy secondary to chemotherapy during childhood was poorly managed and she had missed the opportunity to discuss her reproductive plans and have her periconceptional care delivered. This case emphasises the challenges in engaging Adolescent and Young Adult-aged (AYA-aged) cancer survivors with their healthcare and the importance of narrative medicine, adequate health literacy and early transition to adult services for improved medical care.
\end{abstract}

Key Words: Cardiomyopathy, Anthracycline exposure, Fertility discussions, Narrative medicine, Health literacy, Transition of care

\section{INTRODUCTION}

Overall 5-year survival rates for all childhood cancers have significantly improved over 30 years rising from 58\% for those diagnosed between 1975 and 1977 to $83 \%$ for children diagnosed 2005-2011. ${ }^{[1]}$ Contributing to these advancements has been the widespread use of chemotherapeutic agents belonging to the drug class anthracyclines found in more than $50 \%$ of paediatric chemotherapy protocols. ${ }^{[2]}$ However, improvements in survival rates have not been without considerable adverse drug reactions. Since their introduction in the 1960s it has been well recognised that anthracyclines cause cardiac toxicity. ${ }^{[3]}$ The anti-neoplastic effect of an- thracyclines is achieved via their inhibition of DNA synthesis, transcription and replication, however using iron as a co-factor they also generate reactive oxygen species (ROS) which directly damage protein, lipids and DNA causing oxidative stress. Since cardiomyocytes have lower levels of free radical scavenging systems they are more sensitive to ROS induced injury. ${ }^{[4]}$ Cardiac toxicity caused by anthracyclines can present acutely or many years later as either congestive cardiac failure $(\mathrm{CCF})^{[5]}$ or asymptomatic cardiac dysfunction. ${ }^{[6]}$ Many studies have looked at the frequency of CCF subsequent to anthracycline exposure which varies between $0 \%-16 \%$ according to one systematic review which

\footnotetext{
*Correspondence: Rachel Conyers, MBBS, PhD; Email: rachel.conyers@rch.org.au; Address: Children’s Cancer Centre, Royal Children’s Hospital, Flemington Road, Parkville 3052, Melbourne, Australia.
} 
acknowledged limitations in all 25 articles analysed. ${ }^{[7]} \mathrm{A}$ cohort study found 1 in 10 children exposed to cumulative doses of anthracycline greater than $300 \mathrm{mg} / \mathrm{m}^{2}$ developed anthracycline induced cardiotoxicity resulting in $\mathrm{CCF}^{[8]} \mathrm{Of}$ the children exposed to cardiotoxic chemotherapy treatment between 1962 and 2001, 57\% demonstrated cardiac abnormalities. ${ }^{[1]}$ Risk factors for the development of cardiotoxicity include female gender, younger age at exposure, cumulative dose greater than $300 \mathrm{mg} / \mathrm{m}^{2}$ and concomitant mediastinal radiotherapy. ${ }^{[4]}$ Since childhood cancer patients are surviving longer and the risk of developing CCF after anthracycline exposure increases with age long-term follow-up is required to monitor for late effects.

Females with a history of anthracycline exposure are at risk during pregnancy for subclinical cardiac dysfunction to become unmasked. Anthracycline induced cardiomyopathies existing prior to pregnancy are also at risk of deteriorating during this time. ${ }^{[9]}$ Hines et al. conducted a retrospective study looking at pregnancy-associated cardiomyopathy in females treated with cardiotoxic therapy for childhood cancer between 1963-2006. Of the women who had a pre existing diagnosis of anthracycline induced cardiomyopathy prior to pregnancy $(\mathrm{N}=26), 8$ women had deterioration in their cardiac function during pregnancy. ${ }^{[9]}$ Van Dalen et al. conducted a cohort study in 53 female childhood cancer survivors exposed to anthracycline and neither of the 2 subjects with cardiomyopathy prior to pregnancy deteriorated to peripartum CCF. ${ }^{[10]}$ Therefore further research regarding cardiovascular outcomes during pregnancy for females with anthracycline induced cardiomyopathies are needed to help guide patient counseling and management.

This cohort of patients nonetheless requires close following to ensure a safe pregnancy and delivering this specialised care is particularly challenging in the setting of Adolescent health. Adolescent aged cancer survivors dealing with late effects of their chemotherapy, like any adolescent with a chronic illness can often be non-compliant with medical treatments or advice. ${ }^{[11]}$ In addition, adolescent-aged cancer survivors can often engage in multiple risk taking behaviours that compromise their health and continue into adulthood. ${ }^{[12,13]}$ Psychosocial issues including depression and lack of family support further contribute to the complexity of management in these patients. To improve care, adolescent aged cancer survivors need to be empowered to engage in their healthcare. Interventions are required to boost their health literacy and equip them with the skills to make health-decisions. ${ }^{[14]}$ Timely transition of care to adult services that includes patient education has also been shown to improve health outcomes for AYA-patients. ${ }^{[15]}$

Published by Sciedu Press

\section{Case presentation}

A 16-year-old girl presented to her haematology-oncology outpatient late effects clinic appointment and during routine questioning regarding her recent condition was found to be 12 weeks pregnant. The patient had initially presented acutely 8 years earlier with a one-week history of headache, fever and vomiting. After a routine blood test revealed pancytopenia she underwent a diagnostic bone marrow aspirate and immunophenotype confirmed the diagnosis of AML. She was commenced on standard AML chemotherapy according to the Children's Oncology Group AAML0531 study. This study included a backbone of cytarabine, etoposide and the anthracycline daunorubicin. In total, the patient received a cumulative anthracycline dose of $435 \mathrm{mg} / \mathrm{m}^{2}$ and no radiotherapy to the mediastinum.

Following her third cycle of chemotherapy, the patient was re-admitted to hospital with pseudomonal sepsis and severe excoriation of her perineum. On examination she was found to be tachypnoeic, with a gallop rhythm on auscultation and displaced apex beat. Chest X-rays showed cardiomegaly with bilateral pleural effusions indicative of CCF. Echocardiogram revealed a severely dilated left ventricle with ejection fraction of $14 \%$. The etiology of her CCF was thought to be secondary to anthracycline exposure. Whilst trying to stabilise her cardiac function, her pseudomonal perineal infection worsened, progressing to necrotising fasciitis. For adequate stabilisation the patient underwent extensive surgical debridement revealing full thickness necrosis of the labia majorum extending to the right para-anal area and medial thigh, in addition her bowel wall was necrotic requiring hemicolectomy. Despite triple inotrope support, her dilated cardiomyopathy continued to persist with moderate mitral regurgitation and dyssynchronous ventricular contraction with an ejection fraction of $12 \%$. As a final measure to stabilise her cardiac function the decision was made to use biventricular pacing. The benefit of bi-ventricular pacing was enormous and the patient was quickly weaned from inotropic support and discharged from intensive care.

Further chemotherapy courses were withheld given her extensive surgical resection and ongoing cardiomyopathy, together with a bone marrow aspirate showing remission. Relapse of phenotypic AML occurred 2 years after her initial diagnosis necessitating the need for allogeneic bone marrow transplant. A matched sibling donor was available however the transplant regime was attenuated given her significant cardiac co-morbidity. A further relapse occurred a year later for which another reduced intensity matched unrelated donor bone marrow transplantation was performed. Despite significant co-morbidities and aggressive disease, the patient remains in remission, 5 years post therapy. 
Remission is only one aspect of achieving adequate management of adolescent and young adult cancer therapy. Unfortunately, despite successful efforts to stabilise this patient's disease, many aspects of adolescent care were not focused upon in her eight years of medical care. Numerous psychosocial concerns ensued during her adolescence. Her parents divorced, she developed anxiety and depression and began risk-taking behaviours including drinking alcohol to excess, smoking and promiscuity. She disengaged from school and having failed year 10 left to enter the workforce. For a brief time she was involved in an abusive relationship and lived independently from her parents. Throughout this time, she suffered chronic fatigue associated with her dilated cardiomyopathy. Attempts were made to engage the patient and her family with an adolescent physician, however her engagement was intermittent and despite best attempts from the multi disciplinary team involved in her care including mental health services and social work, a consistent therapeutic relationship was not attained.

When the patient was informed at age 15 that she had premature ovarian failure secondary to chemotherapy exposure, ovum storage and the potential for oocyte donation from a sister were discussed. She declined advice to take the oral contraceptive pill and then focused on attempts to achieve a pregnancy. Unfortunately, at this time she was failing to attend oncology and adolescent clinic appointments. As a result, there was no opportunity to re iterate and clarify all the options she had for achieving a pregnancy or to discuss the various co-morbidities that could potentially hamper a safe-pregnancy. As a result, the patient believed she had a limited period of time to become pregnant and so began having unprotected sex with multiple sexual partners. At the time of her presentation to clinic she was unable to determine who had fathered the child. Furthermore, during this appointment there were multiple factors that needed to be addressed. The patient had anaemia ( $\mathrm{Hb} 80 \mathrm{~g} / \mathrm{L}$ ), was not taking pregnancy supplements, had not ceased her antidepressant medication and was still smoking half a packet of cigarettes per day. In addition, she had failed to attend a cardiology clinic for follow up in the preceding 3 months and had run out of her usual cardiac medications. She had not yet been referred to a tertiary maternity service.

Ultimately, the patient's anthracycline induced cardiomyopathy did not result in peripartum CCF and she had an uncomplicated labour. However this outcome could have been vastly different considering the patient's unmanaged cardiomyopathy, risk-taking behaviours and complex psychosocial issues hindering engagement with healthcare services both before and during early pregnancy. Failing to attend multiple appointments and missing the opportunity to discuss her plans for pregnancy contributed to the patient committing to a decision that was not fully informed and that endangered her health. This case highlights some of the major challenges in delivering adolescent care particularly where there is inconsistent parental support and mental health issues are involved. Without adequate support adolescent patients are often disempowered to take responsibility for their own healthcare and are vulnerable to becoming lost in the system.

\section{Discussion}

The importance of the illness narrative has become increasingly topical in recent years. Klienman first described the illness narrative, ${ }^{[16]}$ which differs from a medical history by adding the dimensions of emotion and experience derived from the illness. Therefore, an illness narrative combines equal parts of medicine and humanity and is very effective as the patient is themselves the narrator. One of the greatest assets of teaching and enabling patients to tell their narrative, is the ability to empower the patient and give them the skill set to accurately describe their disease whilst "giving voice to the experience that medicine cannot describe". ${ }^{[17]}$ Narrative medicine is particularly useful in the setting of AYA patient care, enabling the AYA patient to voice their narrative would allow the physician to fundamentally understand past and present health concerns, within the context of the life being lived, at any point in time. ${ }^{[18]}$ Furthermore, inviting a narrative from an AYA patient, can build a solid rapport and create an environment where the AYA patient feels comfortable to ask questions and further understand their medical condition.

An illness narrative approach would have benefitted this patient by allowing her to express her perceived pressure to become pregnant. Open communication between an AYA cancer survivor and their physician, that is sensitive to their maturity and level of independence ${ }^{[19]}$ is essential for establishing what goals of care are important to the patient and clarifying any misconceptions they may have. A more flexible communication style on the part of the healthcare professional has been shown to reduce rejection by the AYA patient of medical advice and increase the likelihood of adherence. ${ }^{[20]}$ Decision-making and risk appraisal skills are still developing for AYA patients ${ }^{[21]}$ who require education from a trusted physician about the benefits of their continued attendance and contribution at follow up appointments. Cohesive family climates are associated with better adherence to medical regimens and attendance at follow-up appointments. Difficulty navigating the healthcare system as an AYA without family and social supports in this case highlights the necessity for AYA patients to be empowered by their physician to tell their story and take ownership of their 
healthcare. AYAs with chronic health concerns can often show a decrease in self-care and adherence to treatments. 11 A solid therapeutic relationship that addressed barriers to presenting for appointments, the consequences of choosing not to attend and practical skills for managing multiple specialist appointments would have empowered the patient in this case to be both able and motivated to participate fully in her own healthcare.

Health literacy refers to the capacity to "obtain, process and understand health information and services in order to make appropriate health decisions". ${ }^{[22]}$ Low health literacy in adults is well known to be associated with misconceptions about a diagnosis and prognosis, which in turn can lead to poor adherence to management plans and greater anxiety levels. ${ }^{[23]}$ However, little is known about how health literacy effects AYA-aged cancer survivors' health outcomes ${ }^{[24]}$ or in fact how they develop health literacy skills at a critical time where they are about to take on from their parents the responsibility for their own healthcare. Whilst AYA aged patients with chronic illness, including AYA-aged cancer survivors dealing with late effects, may demonstrate a desire for a greater degree of autonomy in their healthcare much earlier than compared to their healthy peers, ${ }^{[25]}$ whether they are being equipped with adequate health literacy skills remains unknown. Further research is needed to inform best practice for facilitating the development of adequate health literacy in AYA-aged patients who have survived childhood cancers and are facing chronic health concerns. Undoubtedly, the process is multi-faceted; influenced by parental support, socioeconomic factors, cultural aspects, level of education attained and concurrent mental health issues. An evidence-based intervention to boost targeted health literacy in AYA-aged cancer survivors is an area of need and there is particular interest from patients in technology-based resources. ${ }^{[26]}$ Further educational resources may have assisted the patient in this case re-engage in her healthcare and become prepared for transition to adult healthcare services.

Adequate transition of care, or the move towards transitioning to adult services, may also have been of benefit in this case. Generally the transition of care from paediatric to adult units involves a multi-disciplinary approach involving all treating physicians, allied health and psychosocial professionals. ${ }^{[27]}$ It is widely acknowledged that transition of care is a top priority in ensuring ongoing health benefits to AYA patients. ${ }^{[28]}$ It has been shown that dedicated, well structured transition models that include education to the AYA patient improve quality of life (QoL) health outcomes, Better health outcomes are probably observed because of the improvement in understanding of disease enabled by the education arms of the models, and improved compliance with clinic appointments facilitated by a model that continues to build patient and physician rapport. Despite the multiple benefits to the AYA patient seen with early transition programs, there are still multiple challenges in achieving smooth transition. ${ }^{[29,30]}$ In this case, the complexity of medical needs was juxtaposed with a multiplicity of emerging AYA issues that should have been seen as a red-flag to physicians that the patient was ready to be transitioned to adult care. A timely transition process would have involved co-ordinating her goals of care and current health status with her oncologists, cardiologist, adolescent health physician, psychiatrist, obstetrician and gynaecologist and fertility specialist. The benefit of this coordinated approach would have been the re-engagement of the patient with all health professionals involved in her care and the ability to educate further regarding goals of care and outcomes as the transition to adult care occurred. Most importantly it would have outlined to the patient the severity of her co-morbidities and further enabled conversations around fertility preservation options.

\section{CONFlicts of InTEREST Disclosure}

The authors have declared no conflicts of interest.

\section{REFERENCES}

[1] Miller KD, Siegel RL, Lin CC, et al. Cancer treatment and survivorship statistics, 2016. CA: a cancer journal for clinicians. 2016. http://dx.doi.org/10.3322/caac. 21349

[2] Smith LA, Cornelius VR, Plummer CJ, et al. Cardiotoxicity of anthracycline agents for the treatment of cancer: systematic review and meta-analysis of randomised controlled trials. BMC Cancer. 2010; 10(1): 337. PMid:20587042 http://dx.doi.org/10.1186/147 1-2407-10-337

[3] Bonadonna G, Monfardini S, Marmont AM, et al. Cardiac toxicity of daunorubicin. The Lancet. 1969; 293(7599): 837-838. http://dx.doi.org/10.1016/S0140-6736(69) 92093-5
[4] Lipshultz SE, Alvarez JA, Scully RE. Anthracycline associated cardiotoxicity in survivors of childhood cancer. Heart. 2008; 94(4): 525-533. PMid:18347383 http://dx.doi.org/10.1136/hrt.2 007.136093

[5] Von Hoff DD. Risk factors for Doxorubin-induced Congestive heart failure. Annals of Internal Medicine. 1979; 91: 717. http: //dx.doi.org/10.7326/0003-4819-91-5-710

[6] Lipshultz SE, Lipsitz SR, Sallan SE, et al. Chronic progressive cardiac dysfunction years after doxorubicin therapy for childhood acute lymphoblastic leukemia. Journal of Clinical Oncology. 2005; 23(12): 2629-2636. PMid:15837978 http://dx.doi .org/10.1200/JCO .2005 .12 .121 
[7] Kremer L, Dalen E, Offringa $\mathrm{M}$ et al. Frequency and risk factors of anthracycline-induced clinical heart failure in children: a systematic review. Ann Oncol. 2002; 13: 503-512. PMid:12056699 http://dx.doi.org/10.1093/annonc/mdf118

[8] van Dalen EC, van der Pal HJH, Kok WEM, et al. Clinical heart failure in a cohort of children treated with anthracyclines: a longterm follow-up study. European Journal of Cancer. 2006; 42(18): 3191-3198. PMid:16987655 http://dx.doi.org/10.1016/j.e jca. 2006.08.005

[9] Hines MR, Mulrooney DA, Hudson MM, et al. Pregnancy-associated cardiomyopathy in survivors of childhood cancer. Journal of Cancer Survivorship. 2016; 10(1): 113-121. PMid:26044903 http: //dx.doi.org/10.1007/s11764-015-0457-8

[10] van Dalen EC, van der Pal HJH, van den Bos C, et al. Clinical heart failure during pregnancy and delivery in a cohort of female childhood cancer survivors treated with anthracyclines. European Journal of Cancer. 2006; 42(15): 2549-2553. PMid:16919450 http://dx.doi.org/10.1016/j.ejca.2006.04.014

[11] Fiese BH, Everhart RS. Medical adherence and childhood chronic illness: family daily management skills and emotional climate as emerging contributors. Current Opinion in Pediatrics. 2006; 18(5) 551-557. PMid:16969171 http://dx.doi.org/10.1097/01.mo p.0000245357.68207.9b

[12] Tercyak K, Donze J, Prahlad S, et al. Multiple behavioral risk factors among adolescent survivors of childhood cancer in the Survivor Health and Resilience Education (SHARE) Program. Pediatr Blood Cancer. 2006; 47: 825-830. PMid:16333821 http://dx.doi.org /10.1002/pbc. 20602

[13] Cantrell M, Posner M. Engagement in High-Risk Behaviors Among Young Adult Survivors of Childhood Cancer Compared to Healthy Same-Age Peers Surveyed in the National Longitudinal Study of Adolescent Health. J Adolesc Young Adult Oncol. 2016; 5: 14651. PMid:26863292 http://dx.doi.org/10.1089/jayao.201 5.0053

[14] Pugh G, Gravestock HL, Hough RE, et al. Health Behavior Change Interventions for Teenage and Young Adult Cancer Survivors: A Systematic Review. Journal of Adolescent and Young Adult Oncology. 2016; 5(2): 91-105. PMid:26871647 http://dx.doi .org/10.10 89/jayao. 2015.0042

[15] Nathan P, Hayes-Lattin B, Sisler J, et al. Critical issues in transition and survivorship for adolescents and young adults with cancers. Cancer. 2011; 117: 2335-2341. PMid:21523755 http://dx.doi .org /10.1002/cncr. 26042

[16] Kleinman A. The Illness Narratives: Suffering, Healing, and the Human Condition. New York: Basic. 1988.

[17] Frank AW. Illness and Autobiographical Work: Dialogue as Narrative Destabilization. Qualitative Sociology. 2000; 23: 135-156. http://dx.doi.org/10.1023/A: 1005411818318

[18] Whitaker K. Medicinal narratives. The Stanford Medical Student Clinical Journal. 2007; 11: 12-13.
[19] Ferrari A, Thomas D, Franklin ARK, et al. Starting an adolescent and young adult program: some success stories and some obstacles to overcome. Journal of Clinical Oncology. 2010; 28(32): 48504857. PMid:20479411 http://dx.doi.org/10.1200/JC0. 200 9.23.8097

[20] D'Agostino N, Penney, Zebrack B. Providing developmentally appropriate psychosocial care to adolescent and young adult cancer survivors. Cancer. 2011; 117: 2329-34. PMid:21523754 http: //dx.doi.org/10.1002/cncr. 26043

[21] Siembida E, Bellizzi K. The Doctor-Patient Relationship in the Adolescent Cancer Setting: A Developmentally Focused Literature Review. J Adolesc Young Adult Oncol. 2015; 4: 108117. PMid:26812664 http://dx.doi.org/10.1089/jayao. 201 5.0011

[22] Nielsen-Bohlman L. Health literacy: a prescription to end confusion. Institute of Medicine (U.S.), Committee on Health Literacy Staff Washington, DC: National Academies Press. 2004.

[23] Koay K, Schofield P, Jefford M. Importance of health literacy in oncology. Asia-Pacific Journal of Clinical Oncology. 2012; 8: 1423. PMid:22369440 http://dx.doi.org/10.1111/j.1743-7 563.2012.01522.x

[24] Sansom-Daly UM, Lin M, Robertson EG, et al. Health Literacy in Adolescents and Young Adults: An Updated Review. Journal of Adolescent and Young Adult Oncology. 2016. http://dx.doi.org/1 $0.1089 /$ jayao.2015.0059

[25] Sawyer S, Aroni R. Self-management in adolescents with chronic illness. What does it mean and how can it be achieved? Med J Aust. 2005; 183: 405-409. PMid:16225444

[26] Berg C, Stratton E, Esiashvili N, et al. Young Adult Cancer Survivors' Experience with Cancer Treatment and Follow-Up Care and Perceptions of Barriers to Engaging in Recommended Care. J Cancer Educ. 2015; 31: 430-442. PMid:25948413 http://dx . doi .org/1 $0.1007 / \mathrm{s} 13187-015-0853-9$

[27] American Academy of Paediatrics. Supporting the Health Care Transition From Adolescence to Adulthood in the Medical Home. Paediatrics. 2011; 128: 182-200. PMid:21708806

[28] Freyer D. Transition of Care for Young Adult Survivors of Childhood and Adolescent Cancer: Rationale and Approaches. J Clin Oncol. 2010; 28: 4810-4818. PMid:20351333 http://dx.doi.org/10. 1200/JC0. 2009.23.4278

[29] McInally W, Cruickshank S. Transition from child to adult services for young people with cancer. Nurs Child Young People. 2013; 25: 14-8. PMid:23520948 http://dx.doi.org/10.7748/ncyp2013. 02.25 .1 .14 .59534

[30] Szalda D, Pierce L, Hobbie W, et al. Engagement and experience with cancer-related follow-up care among young adult survivors of childhood cancer after transfer to adult care. Journal of Cancer Survivorship. 2016; 10(2): 342-350. PMid:26303367 http://dx.doi.org/10.1007/s11764-015-0480-9 